\title{
Chromosome Behaviors in Meiosis of the Inter-specific Hybrids between Colocasia esculenta (L.) Schott and C. gigantea Hook. f.
}

\author{
Hiroshi Okada and G. Gregori Hambali ${ }^{2}$ \\ 'Department of Biology, College of General Education, Osaka \\ University, Osaka 560, Japan \\ ${ }^{2}$ Lembaga Biologi Nasional, Bogor, Indonesia
}

Accepted July 18, 1988

Cultivars of Colocasia esculenta (L.) Schott are well known as one of the very important tropical and subtropical tuber crops, so-called taro. They show many variations not only in size, taste, edible parts, physiology and etc, but also in ploidy, namely diploid and triploid (Hotta 1971, Ramachandran 1978, cf. Moore 1973, Fedorov 1974). For improvement of taro it is necessary to understand what phenomena happened in the process of diversity of cultivars. The cytogenetical information is one of the very important aspects for the purpose. Very few cytological approaches, however, have been applied to generate new taro cultivars (Ramachandran 1978).

We have carried out the crossing test between Colocasia esculenta and $C$. gigantea aiming the increase of cytogenetical information of taro, and successfully obtained both diploid and triploid $F_{1}$ hybrids between both species. In this paper we describe the features of the meiotic chromosome behaviors of both diploid and triploid hybrids.

\section{Materials and methods}

\section{Crossing procedures}

Colocasia esculenta (L.) Schott cultivar "Burkok" and $C$. gigantea Hook. f. in the living collections of Bogor Botanical Garden, Indonesia, were used for the parental materials. The male part of the protogynous inflorescence of $C$. esculenta was first removed at anthesis. There is no possibility of self-pollination, because of the protogynous dichogamy of the species. The collected pollen grains of $C$. gigantea were dusted on the stigmatic surface of the female part of the emasculated inflorescence and bagged. After six weeks the seeds matured. Both diploid and triploid hybrids appeared to be weak and survived only with heavy fertilizer applications at Bogor Botanical Garden. We obtained 15 mature individuals.

\section{Chromosome observations}

The observations of somatic metaphase chromosome were carried out by the conventional techniques, such as the methods mentioned by Lubis et al. (1981).

For the observations of the chromosome behavior at meiosis, young inflorescences were fixed by the fresh modified Carnoy's fluid, the mixture of 2 parts of absolute EtOH, 1 part of chloroform and 1 part of glacial acetic acid, for more than $30 \mathrm{~min}$. Pollen mother cells (PMCs) were collected on a slide glass and stained with $2 \%$ aceto-orcein for over $5 \mathrm{~min}$. They were then squashed gently, and observed. Pollen grain fertility was calculated based on the preparations stained with aceto-carmine. Fertile pollen grains stained darkly, and were globular in shape.

\footnotetext{
2 Present address: Salacca Breeding Hut, J1. Arca Domas 7, Bogor Timur, P. O. Box 8, Indonesia.
} 


\section{Results and discussion}

\section{Mitotic chromosome complements}

Many authors have reported the chromosome numbers of both $C$. esculenta and $C$. gigantea (Kurakubo 1940, Ito 1942, Hotta 1971, Ramachandran 1978, cf. Darlington and Wylie 1955, Moore 1973, Fedorov 1974). According to these reports, both species show $2 n=28$ and 42 , which are the diploid and triploid level of $x=14$, respectively. In this study, the chromosome numbers of both maternal individual of $C$. esculenta and paternal individual of $C$. gigantea were confirmed to be $2 \mathrm{n}=28$ (Fig. 1A, B), diploid level.

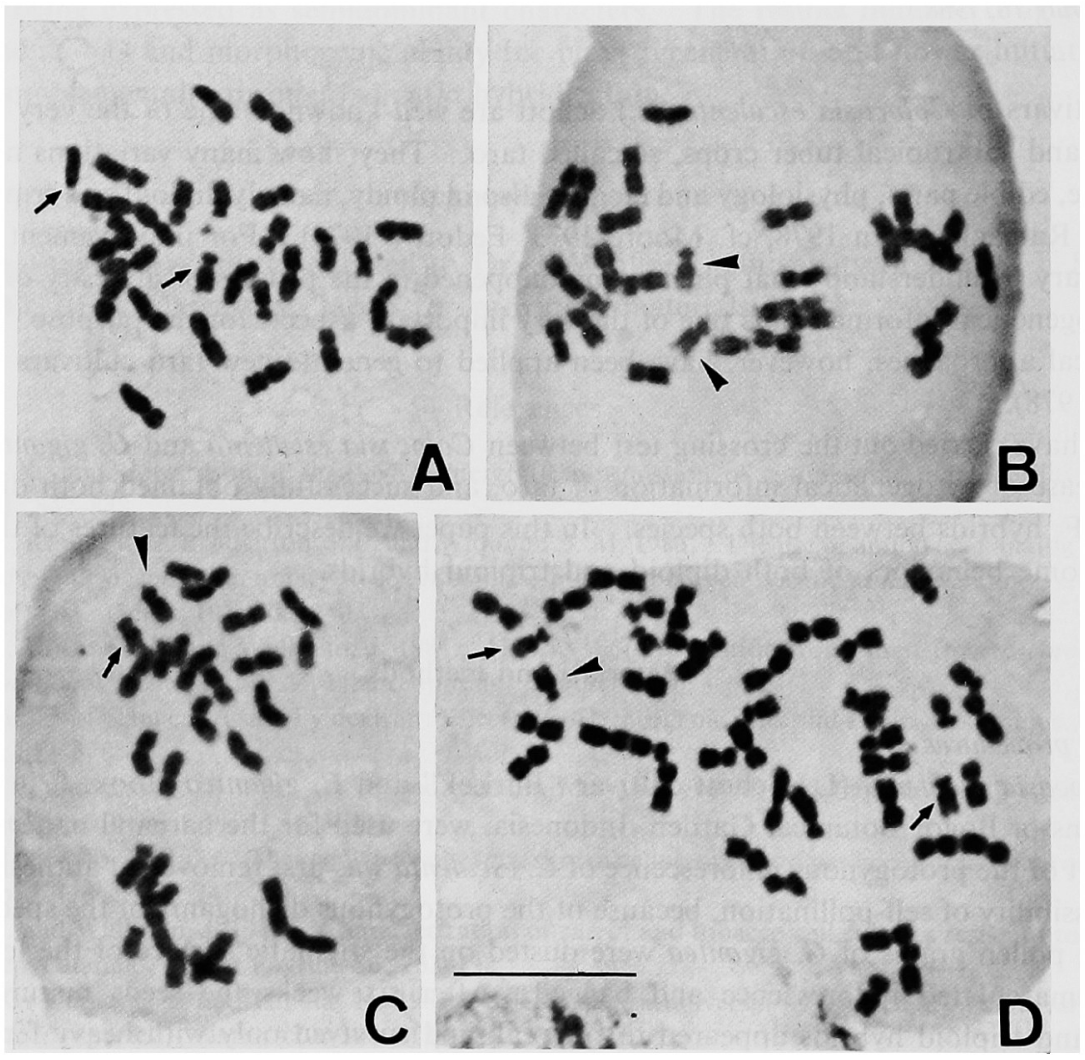

Fig. 1. Photomicrographs showing somatic metaphase chromosomes. A; C. esculenta, $2 \mathrm{n}=28$. B; C. gigantea, $2 n=28$. C; diploid hybrid, $2 n=28$. D; triploid hybrid, $2 n=42$. Arrows indicate satellite chromosomes of $C$. esculenta. Arrowheads indicate those of $C$. gigantea. Bar: $10 \mu \mathrm{m}$.

The chromosome complement of $C$. esculenta consisted of 11 pairs of metacentric chromosome and 3 pairs of acrocentric one (Fig. 2A). One of acrocentric chromosomes (8th pair) possessed the satellite of ca. 0.4 to $0.3 \mu \mathrm{m}$ in length at the distal end of the short arm. The length of the chromosomes at metaphase varied, ranging from ca. 4.0 to $2.5 \mu \mathrm{m}$.

The chromosome complemenent of $C$. gigantea was almost the same as that of $C$. esculenta (Fig. 2B). The satellite of 8 th pair of this species was smaller than that of $C$. esculenta, less than ca. $0.2, u \mathrm{~m}$ in length. The size differential of the satellites was used to identify the origin of the chromosome complement (Fig. 2A, B).

Fourteen of $15 F_{1}$ hybrid individuals had $2 n=28$, the diploid level (Fig. 1C). They showed the heterogeneity on the pair of satellite chromosomes. One satellite chromosome 
had a bigger satellite and the other a smaller satellite. This indicates that these hybrids consist evenly of one chromosome set from each parent.

Among 15 individuals of $F_{1}$ hybrid, one showed $2 n=42$, the triploid level (Fig. 1D). This individual possessed two chromosomes with a bigger satellites and one with a smaller one. Therefore, it is concluded that the triploid hybrid consisted of 2 chromosome sets of $C$. esculenta and 1 set of $C$. gigantea. It is preseumed that an egg cell of $C$. esculenta occurred at the diploid level by a phenomenon of secondary junction of divided cells or accidental nondisjunction in meiotic stages. There are some instances of triploid C. esculenta in cultivars (Hotta 1971, Ramachandran 1978) and in nature (Chakroborty and Bhattacharya 1984), which might arise from similar processes.

\section{Chromosome behaviors at diakinesis or metaphase I of PMCs}

Diploid hybrids showed that almost all chromosomes did not form any chromosome pairings, but formed univalents, except a couple of chromosome (Fig. 3A, B; Table 1). In

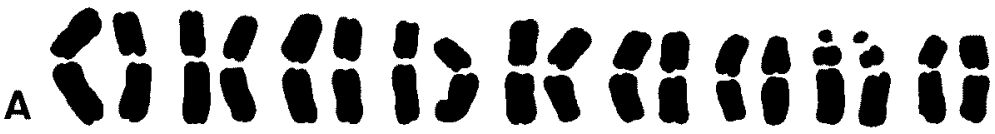 if ii ii itio $\left.\quad\right|^{\text {sn }}$

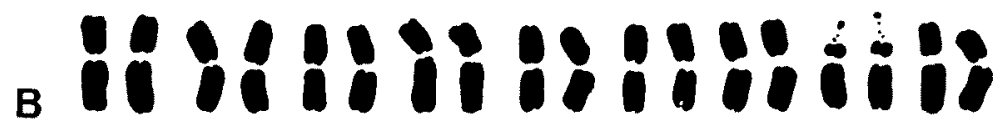 Ai iiviaid io}

Fig. 2. Somatic metaphase chromosomes of C. esculenta, $2 n=28$ (A) and C. gigantea, $2 n=28$ (B). Both species show almost the same chromosome complement, exception for the size of satellite of satellite chromosome (8th pair). Bar: $5 \mu \mathrm{m}$.

spite of the similar morphology of mitotic chromosomes (Fig. 2A, B), almost all chromosomes of both species may have no affinity concerning the pairing sites. A few exceptional chromosomes formed bivalents and might have exchanged genes to each other by chiamsa formation. Occasionally one or two trivalents were observed.

These meiotic abnormalities gave rise to germ cells which were almost all sterile. The rate of good pollen grains of diploid hybrids was approximately only $1-2 \%$.

These results suggest that chromosomal differentiation accompanied with speciation of both species do not appear as the dissimilarity of mitotic chromosomes, but do as the scanty affinity for pair formation. The reproductive isolation is perfectly performed.

On the contrary, the triploid hybrid showed a different chromosome behavior in meiosis from diploid ones (Fig. 3C, D; Table 2). The number of bivalents ranged from 11 to 15 (mean 13.2), while that of univalents ranged from 10 to 16 (mean 13.2). All of these bivalents may be formed by the homologous chromosome pairs of $C$. esculenta, while all univalents may be originated from chromosomes of $C$. gigantea. Very few trivalents and/or quadrivalents were 


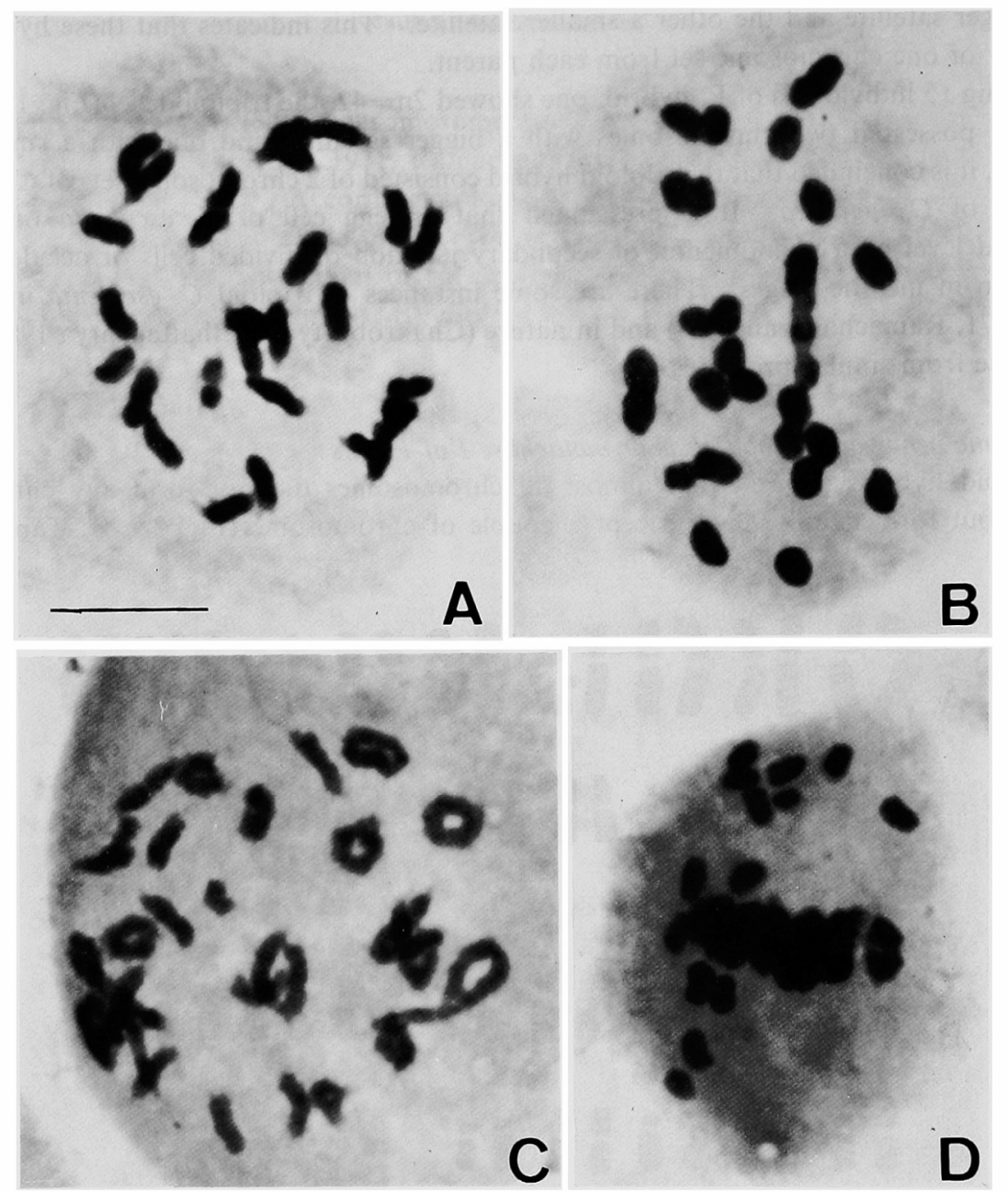

Fig. 3. Photomicrographs showing chromosome pairings of PMCs of both diploid $(A, B)$ and triploid (C, D) hybrids. A, C; diakinesis. B, D; metaphase I. A; $2_{1 I}+24_{I}$. B; $1_{I I}+26_{I}$. C; $1_{\text {III }}+13_{\text {II }}+13_{\text {I }}$. D; $14_{\text {II }}+14_{\text {I. }}$ Bar: $10 \mu \mathrm{m}$.

Table 1. The frequencies of the pairing forms of PMCs of a diploid hybrid

\begin{tabular}{rc}
\hline \hline Pairing form & Cell number \\
\hline $1_{\mathrm{III}}+2_{\mathrm{II}}+21_{\mathrm{I}}$ & 4 \\
$1_{\mathrm{III}}+1_{\mathrm{II}}+23_{\mathrm{I}}$ & 1 \\
$1_{\mathrm{III}}+25_{\mathrm{I}}$ & 2 \\
$3_{\mathrm{II}}+22_{\mathrm{I}}$ & 6 \\
$2_{\mathrm{II}}+24_{\mathrm{I}}$ & 12 \\
$1_{\mathrm{II}}+26_{\mathrm{I}}$ & 24 \\
$28_{\mathrm{I}}$ & 10 \\
\hline
\end{tabular}

Table 2. The frequencies of the pairing forms of PMCs of a triploid hybrid

\begin{tabular}{rc}
\hline \hline Pairing form & Cell number \\
\hline $1_{\mathrm{IV}}+1_{\mathrm{III}}+12_{\mathrm{II}}+11_{\mathrm{I}}$ & 3 \\
$1_{\mathrm{IV}}+1_{\mathrm{III}}+11_{\mathrm{II}}+13_{\mathrm{I}}$ & 1 \\
$1_{\mathrm{IV}}+13_{\mathrm{II}}+12_{\mathrm{I}}$ & 5 \\
$1_{\mathrm{IV}}+12_{\mathrm{II}}+14_{\mathrm{I}}$ & 3 \\
$3_{\mathrm{III}}+11_{\mathrm{II}}+11_{\mathrm{I}}$ & 1 \\
$2_{\mathrm{III}}+13_{\mathrm{II}}+10_{\mathrm{I}}$ & 1 \\
$2_{\mathrm{III}}+12_{\mathrm{II}}+12_{\mathrm{I}}$ & 1 \\
$1_{\mathrm{III}}+13_{\mathrm{II}}+13_{\mathrm{I}}$ & 15 \\
$1_{\mathrm{III}}+12_{\mathrm{II}}+15_{\mathrm{I}}$ & 1 \\
$15_{\mathrm{II}}+12_{\mathrm{I}}$ & 6 \\
$14_{\mathrm{II}}+14_{\mathrm{I}}$ & 9 \\
$13_{\mathrm{II}}+16_{\mathrm{I}}$ & 6 \\
\hline
\end{tabular}


observed. The number ratio of trivalents and quadrivalents of the triploid hybrid corresponded to the number ratio of bivalents and trivalents of the diploid hybrid (Tables 1,2). Multivalents might arise from the aggregation of the chromosomes of the parents plus one or two chromosomes of C. esculenta. Actually it seems to be natural to consider that the the affinitive chromosomes between both species form bivalents in the case of diploid hybrids, while trivalents in the case of a triploid hybrid.

The bivalent formations are effective for increasing the fertility of germ cells in the triploid hybrid. Indeed, the rate of good pollen grains, $21 \%$, becomes about ten times higher than that of the diploid hybrid. Compared with ca. $33 \%$ in triploid C. esculenta (Ramachandran 1978), this value is not so low. It is possible to get variable offsprings from this triploid hybrid.

\section{Summary}

Cytogenetical studies were carried out on the artificial $\mathrm{F}_{1}$ hybrids between Colocasia esculenta $(2 n=28)$ and $C$. gigantea $(2 n=28)$. Of 15 individuals 14 possessed $2 n=28$, the diploid level of $x=14$, while 1 of 15 showed $2 n=42$, the triploid level.

The diploid hybrids contained two chromosome sets, one from each parental species. In spite of the similar morphology of chromosome complements to each other parental species, the PMCs of the diploid hybrids showed an abnormal feature in meiosis; almost all chromosomes formed univalents. This abnormal pairing form resulted in the complete sterility of its pollen grains.

The triploid hybrid contained two chromosome sets from $C$. esculenta and one set from C. gigantea. The PMCs of triploid hybrid showed strikingly different aspects in meiosis from those of diploid hybrids; homologous chromosomes of $C$. esculenta formed bivalents, while chromosomes of $C$. gigantea formed univalents. The rate of good pollen grains increased to $21 \%$.

\section{Acknowledgements}

Senior author, Okada, wishes to express his deep appreciation to Dr. S. Sastrapradja, Director of LBN, Indonesia, and Dr. T. M. Koyama, Prof. of New York Botanical Garden, who arranged his stay in Bogor, Indonesia. His thanks are also due to Mr. Jeffrey Silverstein, former Guest Researcher of Osaka University, for a linguistic check. This study was supported in part by the Toyota Foundation Grant No. 781-1-013, assigned to Dr. T. M. Koyama.

\section{References}

Chakroborty, B. N. and Bhattacharya, G. N. 1984. Desynapsis as well as inversion heterozygosity in the natural population of triploid Colocasia antiquorum Schott. Cytologia 49: 739-743.

Darlington, C. D. and Wylie, A. P. 1955. Chromosome Atlas of Flowering Plants. 2nd ed. Allen and Unwin, London.

Fedorov, A. 1974. Chromosome Numbers of Flowering Plants. Otto Koelts Sci. Pub., Koenigstein.

Hotta, M. 1971. Study of the family Araceae: general remarks. Jap. Journ. Bot. 20: 269-310.

Ito, T. 1942. Chromosomen und Sexualität von der Araceae I. Somatische Chromosomenzahlen einiger Arten. Cytologia 12: 313-325.

Kurakubo, Y. 1940. Über die Chromosomenzahlen von Araceae-Arten. Bot. and Zool. (Tokyo) 8 : 1492.

Lubis, S. H. A., Okada, H. and Sastrapradja, S. 1981. On the cytology of four species of Sesbania. Ann. Bogor. 7: 115-127.

Moore, R. J. 1973. Index to Plant Chromosome Numbers 1967-1971. IAPT, Utrecht.

Ramachandran, K. 1978. Cytological studies on south Indian Araceae. Cytologia 43: 289-303. 